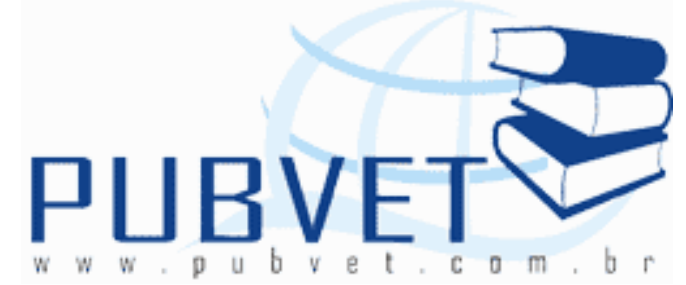

PUBVET, Publicações em Medicina Veterinária e Zootecnia.

\title{
Alterações renais em cães alimentados com diferentes dietas
}

Cláudio Henrique Gonçalves Barbosa ${ }^{1}$, Gustavo Delfino Xavier ${ }^{2}$, Maria Isabel Teixeira da Silva ${ }^{2}$, Humberto Eustáquio Coelho ${ }^{3}$, Tatiane Furtado de Carvalho ${ }^{4}$, Hélio Alberto ${ }^{5}$, Flavia Maria Esteves Machado ${ }^{6}$

${ }^{1}$ Aluno Bolsista de Graduação em Medicina Veterinária pela Universidade de Uberaba (UNIUBE) - Uberaba/MG, e-mail: claudiohgb.vet@gmail.com;

${ }^{2}$ Aluno de Graduação em Medicina Veterinária pela UNIUBE

${ }^{3}$ Médico Veterinário, Mestre, Doutor, Professor de Patologia Geral, Especial e Ornitopatologia da UNIUBE, e-mail: coelhoheust@yahoo.com.br;

${ }^{4}$ Residente de Patologia Animal do Hospital Veterinário de Uberaba (HVU)

${ }^{5}$ Técnico do Laboratório de Anatomia Patológica do HVU

${ }^{6}$ Médica Veterinária, Doutora, Professora de Zoonoses e Epidemiologia na UNIUBE,e-mail:festeves@mednet.com.br

\section{Resumo}

Foram estudados 172 cães de ambos os sexos, de raças e idades variadas, que morrerem no Hospital Veterinário de Uberaba (HVU), cujas alimentações eram compostas de uma dieta de ração (grupo 1), de comida caseira (grupo 2) e mista (grupo 3). Os rins de todos os animais foram examinados macroscopicamente, colhidos fragmentos dos mesmos para posterior exame histopatológico. Fragmentos dos rins foram fixados em formol 10\%, desidratados, diafonizados, incluídos em parafina e cortados a 6 micrometros 
BARBOSA, C.H.G. et al. Alterações renais em cães alimentados com diferentes dietas.

PUBVET, Londrina, V. 6, N. 34, Ed. 221, Art. 1471, 2012.

de espessura, corados em Hematoxilina e Eosina, e posterior exame à luz da microscopia óptica. Por fim, foi realizada analise para confirmação de significância estatística. Nos três grupos, ficou evidenciada como alteração de maior proporção a glomerulonefrite e o tipo de alimentação não influenciou diretamente nas alterações renais dos cães avaliados.

Palavras-chave: rins, glomerulonefrite, ração, comida caseira, histopatológico

\title{
Kidney disorders in dogs fed different diets
}

\begin{abstract}
We studied 172 dogs of both sexes and various ages and races, who died at the Veterinary Hospital of Uberaba (HVU) whose feeds were composed of a diet of feed (group 1), homemade food (group 2) and mixed (group 3). The kidneys of all animals were examined macroscopically, collected fragments thereof for subsequent histopathological examination. Fragments of the kidneys were fixed in $10 \%$ formalin, dehydrated, diafonizados, embedded in paraffin and cut at 6 microns thick, stained with hematoxylin and eosin, and later examined in the light optical microscopy. Finally, analysis was performed to confirm statistical significance. In all three groups was evident as a change of major proportion glomerulonephritis and type of food does not directly influence renal dogs evaluated.
\end{abstract}

Keywords: kidneys, glomerulonephritis, food, homemade food, histopathological

\section{INTRODUÇÃO}

As alterações renais reúnem um conjunto de lesões no parênquima renal desde uma simples degeneração até uma nefrite ou mesmo uma neoplasia. Tudo isto implica diretamente com a função renal, rotulada por insuficiência renal, que pode ser aguda ou crônica ${ }^{1}$. 
BARBOSA, C.H.G. et al. Alterações renais em cães alimentados com diferentes dietas. PUBVET, Londrina, V. 6, N. 34, Ed. 221, Art. 1471, 2012.

A insuficiência renal é uma condição patológica devida a uma perda da capacidade funcional do rim, mais ou menos completa ou irreversível. Ela pode ser aguda ou crônica².

Todas as funções vitais dos rins sofrem com a perda progressiva dos néfrons, mas os sinais clínicos mais importantes provêm do acúmulo de produtos da degradação das proteínas (azotemia), já que a taxa de filtração glomerular e a concentração de uréia sangüínea são uma constante, de forma que a queda em destes valores causará o aumento do outro. Geralmente é aceito que os sinais de azotemia não são devidos a uma única substância nitrogenada, mas a todos os produtos do catabolismo protéico junto (uréia, creatinina, guanidina, ácidos fenólicos e seus conjugados, potássio e fosfatos). Entretanto o nível de uréia sangüínea indica a severidade da insuficiência renal ${ }^{3}$.

A insuficiência renal crônica em cães e gatos é um problema comum, a qual afeta principalmente a população de animais velhos ${ }^{4}$.

Os casos avançados de insuficiência renal podem desencadear severas crises urêmicas que necessitam de tratamento intensivo imediato ${ }^{5,6,7}$.

Os sinais clínicos mais comuns de insuficiência renal crônica são: polidipsia, aumento do consumo de água, poliúria e micções freqüentes, letargia, anorexia, perda de peso, vômitos, diarréia, úlcera gástrica, mau hálito, fraqueza e intolerância ao exercício ${ }^{8}$.

A amiloidose renal possui grande significado clínico pelo fato de causar doença renal crônica irreversível e síndrome nefrótica. Nestas situações, não ocorre regeneração efetiva dos néfrons lesados devido à deposição progressiva de amilóide nos glomérulos com conseqüente fibrose $9,10,11,12$.

Segundo a Associação Nacional dos Fabricantes de Alimentos para Animais, existem no Brasil cerca de 21 milhões de cães com endereço fixo, a segunda maior população do planeta. Destes, 34\% são alimentados com ração industrializada. A produção de alimentos para animais de estimação foi da ordem de 1.234 .000 toneladas no ano de 2002, mantendo crescimento médio anual de $5 \%$ nos últimos 10 anos e com potencial produtivo estimado de 
BARBOSA, C.H.G. et al. Alterações renais em cães alimentados com diferentes dietas.

PUBVET, Londrina, V. 6, N. 34, Ed. 221, Art. 1471, 2012.

3.200.000 toneladas/ano ${ }^{13}$. A ingestão excessiva de cálcio leva a competições desse macro-elemento com outros minerais, como o zinco, durante a absorção intestinal, o que pode ocasionar deficiência de zinco ${ }^{14}$.

A alimentação é via de mão dupla, trás saúde, longevidade e beleza quando é de qualidade. Porém, a falta ou excesso de nutrientes pode atropelar tudo isso, e as doenças se aproximarem tornado a vida abreviada e infeliz. Numerosos estudos sobre nutrição canina indicam problemas causados pelo suprimento inadequado de proteínas, carboidratos gorduras, minerais e vitaminas.

Assim sendo, objetiva-se, com a presente pesquisa, correlacionar o tipo de alimentação com as prováveis alterações renais, que comprometem a função do mesmo, através de análise histopatológica, em microscopia óptica, das lâminas obtidas a partir dos cortes histológicos dos rins dos cães observados.

\section{METODOLOGIA}

Foram estudados 172 cães de ambos os sexos, de raças e idades variadas, que morreram no Hospital Veterinário de Uberaba (HVU), no período de agosto de 2008 a junho de 2009.

Foram anotadas as dietas de cada animal, segundo o seguinte critério: (1) Animal com dieta exclusivamente de ração; (2) Animal com dieta exclusivamente de comida caseira; (3) Animal com dieta mista de ração e comida caseira. Este critério foi estabelecido com base nas informações fornecidas pelos proprietários dos animais durante a consulta clínica e constam no sistema de informações do HVU; não sendo especificado pelos proprietários a frequência da alimentação, a marca da ração fornecida nem sua quantidade, bem como quais os alimentos que compunham a "dieta caseira".

Realizou se o exame, macroscópico dos rins de todos e cada um dos animais. Foram colhidos fragmentos dos rins, estes foram fixados em formol 10\%, desidratados, diafonizados, incluídos em parafina e cortados a 6 micrometros de espessura, corados em Hematoxilina e Eosina. Depois desse 
BARBOSA, C.H.G. et al. Alterações renais em cães alimentados com diferentes dietas. PUBVET, Londrina, V. 6, N. 34, Ed. 221, Art. 1471, 2012.

procedimento foi realizado o exame histopatológico a luz de microscópio óptico, os resultados obtidos foram catalogados e deram origem as tabelas para a análise estatística e comparativa entre as alterações e as diferentes dietas.

\section{RESULTADOS}

Através dos dados obtidos nos exames macroscópico e histopatológicos foram montadas as tabelas (Figuras 1, 2, 3) que descrevem as alterações observadas, suas ocorrências nos cães alimentados com diferentes dietas e a porcentagem dessas alterações no total de lesões encontradas, com a visualização de algumas lâminas histopatológicas das enfermidades, abordadas nas Figuras 4, 5, 6, 7 e 8. 
BARBOSA, C.H.G. et al. Alterações renais em cães alimentados com diferentes dietas.

PUBVET, Londrina, V. 6, N. 34, Ed. 221, Art. 1471, 2012.

Figura1 - Alterações observadas em 90 amostras renais de cães com dieta a base de ração dentre os 172 rins coletados de cães

Alteração

Degeneração Glomerular

Degeneração Hidrópica

Degeneração Tubular

Degeneração Turva

Espessamento de Cápsula renal

Glomerulite

Glomerulonefrite

Hemorragia

Hiperemia

Infarto Renal

Mineralização

Necrose Renal

Necrose glomerular

Necrose tubular

Nefrite aguda

Nefrite crônica

Nefrite intersticial

Nefrite linfoplasmocitária aguda

Nefrite linfoplasmocitária subaguda

Nefrose colêmica

Pielonefrite linfoplasmocitária

Pielonefrite crônica

Retração tubular de cilindros

Hialinos

\section{Dieta a base de Ração}

\begin{tabular}{|c|c|}
\hline Ocorrência & $\%$ \\
\hline 2 & 1,16 \\
\hline 8 & 4,51 \\
\hline 3 & 1,74 \\
\hline 3 & 1,74 \\
\hline- & - \\
\hline 3 & 1,74 \\
\hline 16 & 9,3 \\
\hline 7 & 4,07 \\
\hline 7 & 4,07 \\
\hline 3 & 1,74 \\
\hline 2 & 1,16 \\
\hline- & - \\
\hline 2 & 1,16 \\
\hline 8 & 4,51 \\
\hline 1 & 0,58 \\
\hline 1 & 0,58 \\
\hline 12 & 6,98 \\
\hline 4 & 2,33 \\
\hline 2 & 1,16 \\
\hline 4 & 2,33 \\
\hline- & - \\
\hline 2 & 1,16 \\
\hline- & - \\
\hline 90 & $\overline{52,02}$ \\
\hline
\end{tabular}


BARBOSA, C.H.G. et al. Alterações renais em cães alimentados com diferentes dietas.

PUBVET, Londrina, V. 6, N. 34, Ed. 221, Art. 1471, 2012.

Figura 2 - Alterações observadas em 25 amostras renais de cães com dieta a base de comida caseira dentre os 172 rins coletados de cães

Alteração

Degeneração Glomerular

Degeneração Hidrópica

Degeneração Tubular

Degeneração Turva

Espessamento de Cápsula renal

Glomerulite

Glomerulonefrite

Hemorragia

Hiperemia

Infarto Renal

Mineralização

Necrose Renal

Necrose glomerular

Necrose tubular

Nefrite aguda

Nefrite crônica

Nefrite intersticial

Nefrite linfoplasmocitária aguda

Nefrite linfoplasmocitária subaguda

Nefrose colêmica

Pielonefrite linfoplasmocitária

Pielonefrite crônica

Retração tubular de cilindros

Hialinos

Dieta a base de Comida caseira

$\%$

0,58

1,16

4,07

1,16

1,74

1,16

3,49

6

$-$

-

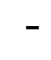

1,16

2

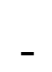


BARBOSA, C.H.G. et al. Alterações renais em cães alimentados com diferentes dietas.

PUBVET, Londrina, V. 6, N. 34, Ed. 221, Art. 1471, 2012.

Figura 3 - Alterações observadas em 57 amostras renais de cães com dieta mista dentre os 172 rins coletados de cães

\section{Alteração}

Degeneração Glomerular

Degeneração Hidrópica

Degeneração Tubular

Degeneração Turva

Espessamento de Cápsula renal

Glomerulite

Glomerulonefrite

Hemorragia

Hiperemia

Infarto Renal

Mineralização

Necrose Renal

Necrose glomerular

Necrose tubular

Nefrite aguda

Nefrite crônica

Nefrite intersticial

Nefrite linfoplasmocitária aguda

Nefrite linfoplasmocitária subaguda

Nefrose colêmica

Pielonefrite linfoplasmocitária

Pielonefrite crônica

Retração tubular de cilindros

Hialinos
Dieta Mista 
BARBOSA, C.H.G. et al. Alterações renais em cães alimentados com diferentes dietas.

PUBVeT, Londrina, V. 6, N. 34, Ed. 221, Art. 1471, 2012.

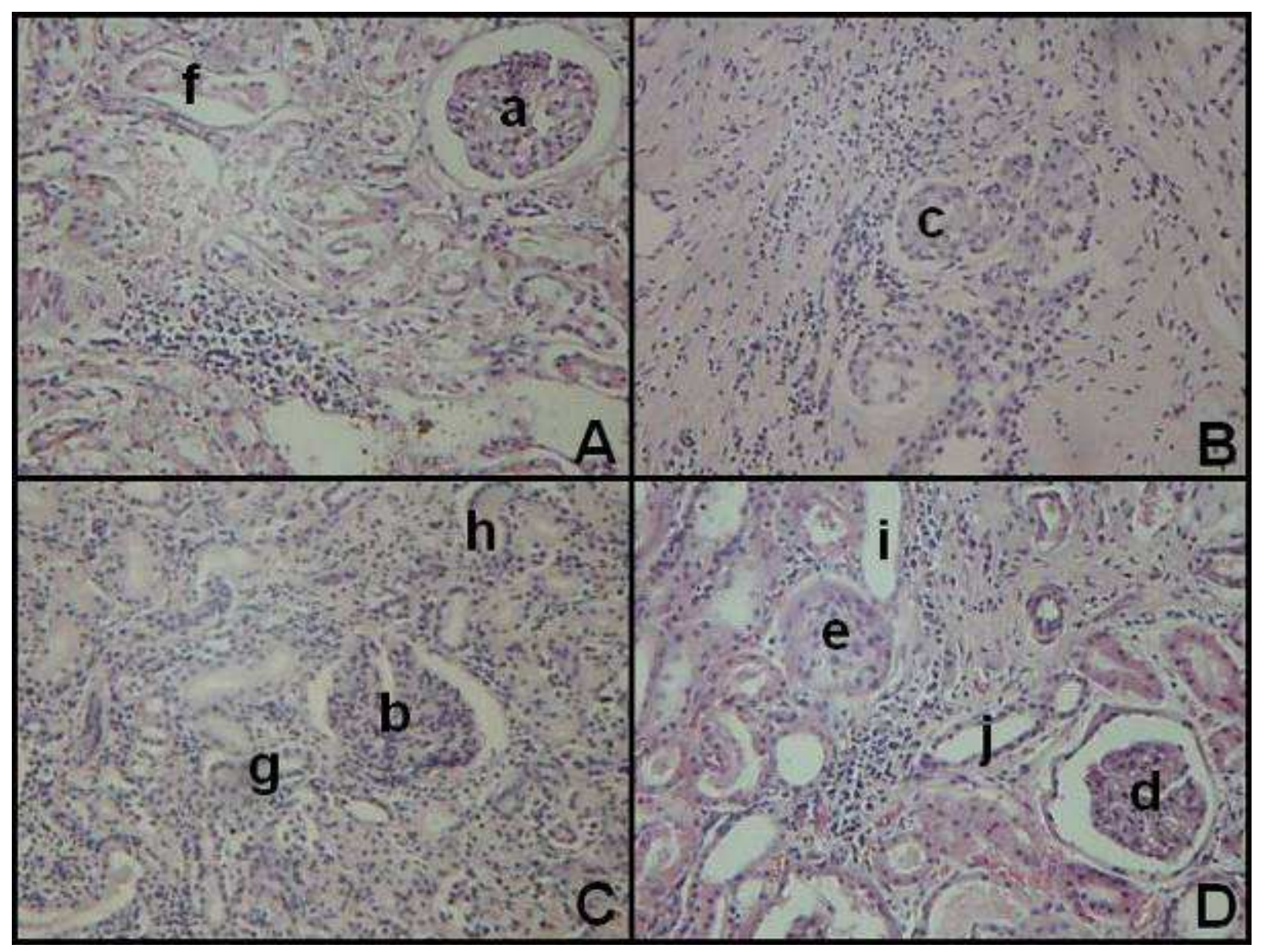

Figura 4 - Lâminas histopatológicas dos rins de cães demonstrando imagens características de glomerulonefrite. Verificar glomerulites ( $a, b, c$, d) pelo descolamento das cápsulas glomerulares e grande quantidade de leucócitos presentes. Imagem de glomérulo com morfologia habitual (e). Nefrites (f, g, h, $\mathrm{i}, \mathrm{j}$ ) pela excessiva apresentação de leucócitos no tecido renal e aumento de volume. Coloração: A, B, C, D: hematoxilina-eosina. Objetiva: A, B, C, D: 20x. Fotógrafos e Proprietários das fotos: Cláudio Henrique Gonçalves Barbosa (4a), Gustavo Delfino Xavier (4b, 4c) e Humberto Eustáquio Coelho (4d). 


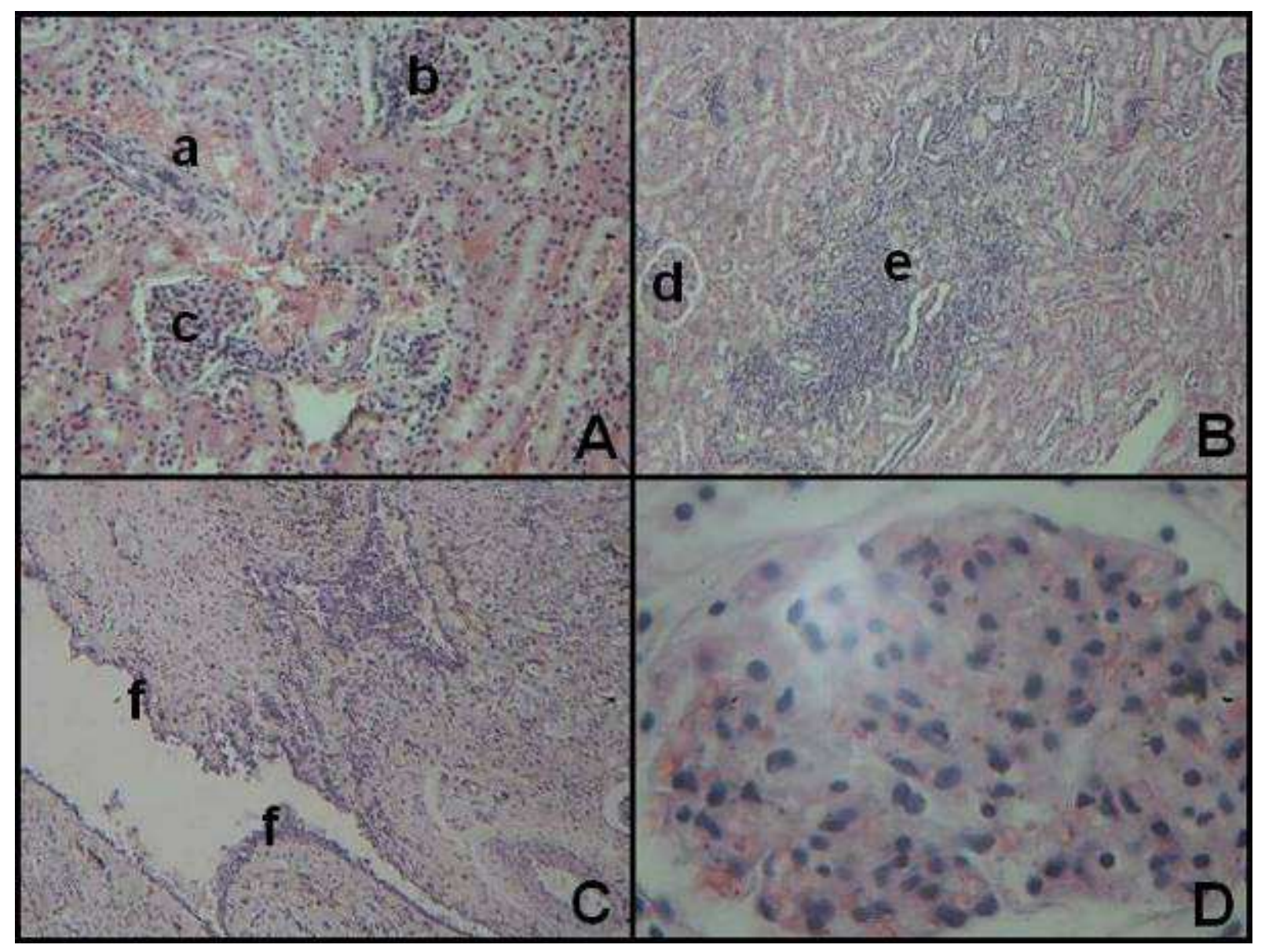

Figura 5 - Lâminas histopatológicas dos rins de cães demonstrando imagens características de glomerulonefrite com Hemorragia (A), Nefrite intersticial focal (B), Pielonefrite (C) e Glomerulite (D). Observar grande quantidade de sangue depositado no tecido renal (a), glomerulites (b, c, d), aumento do volume de leucócitos em área delimitada no tecido renal (e) e presença de grande quantidade de leucócitos com descolamento da cápsula renal (f). Coloração: A, B, C, D: hematoxilina-eosina. Objetiva: A, B, C: 20x; D: 40x. Fotógrafos e Proprietários das fotos: Humberto Eustáquio Coelho (5a, 5c), Cláudio Henrique Gonçalves Barbosa (5b) e Gustavo Delfino Xavier (5d). 
BARBOSA, C.H.G. et al. Alterações renais em cães alimentados com diferentes dietas.

PUBVET, Londrina, V. 6, N. 34, Ed. 221, Art. 1471, 2012.

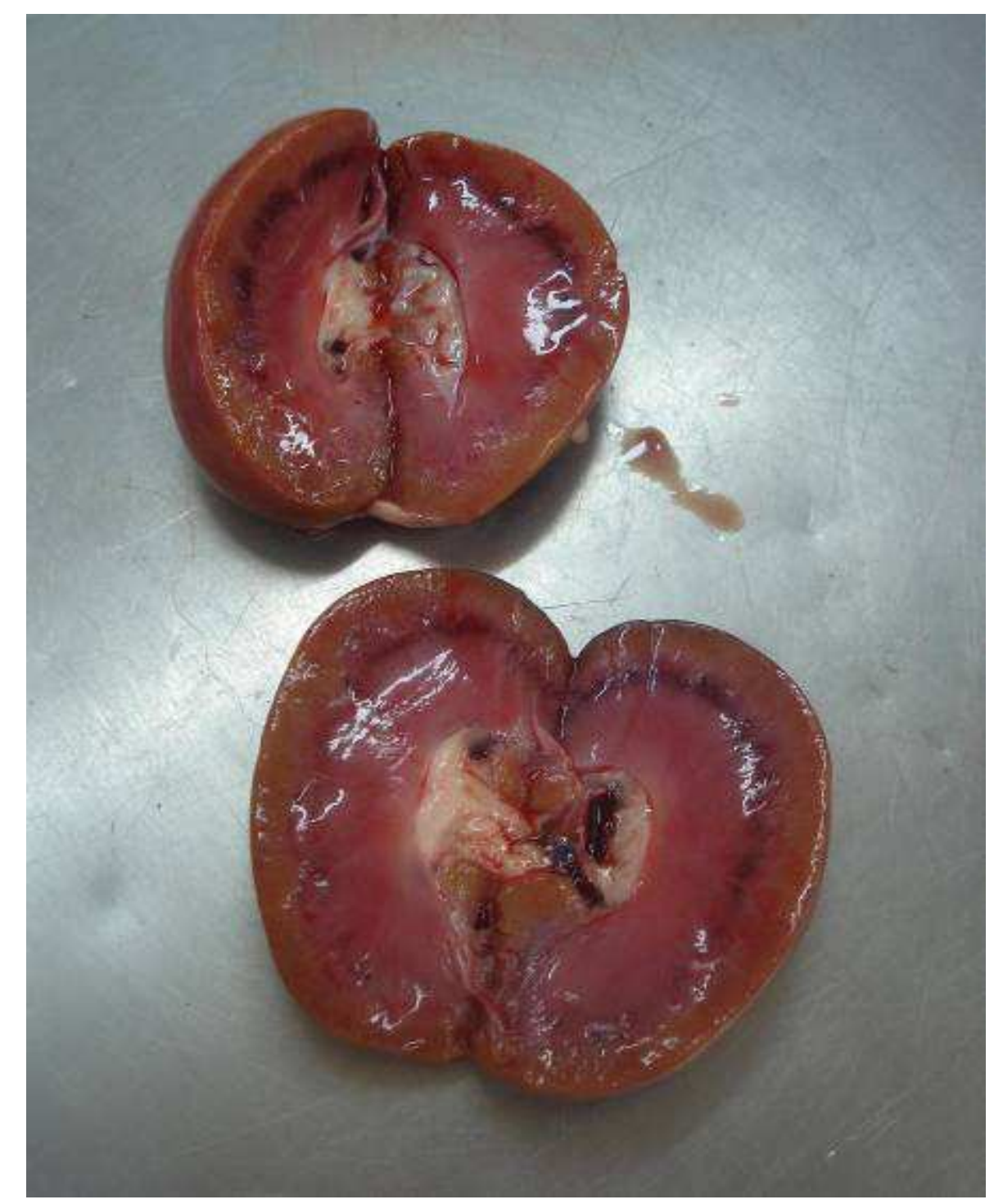

Figura 6 - Amostra renal de um cão, exemplificando rins com nefrite aguda. Observar áreas hiperêmicas nas regiões, cortical e medular. Aumento de volume e ligeira perda da forma habitual. Presença de pequenas áreas hemorrágicas na transição da cortical para medular e no hilo renal. Fotógrafo e Proprietário da foto: Humberto Eustáquio Coelho. 
BARBOSA, C.H.G. et al. Alterações renais em cães alimentados com diferentes dietas.

PUBVET, Londrina, V. 6, N. 34, Ed. 221, Art. 1471, 2012.

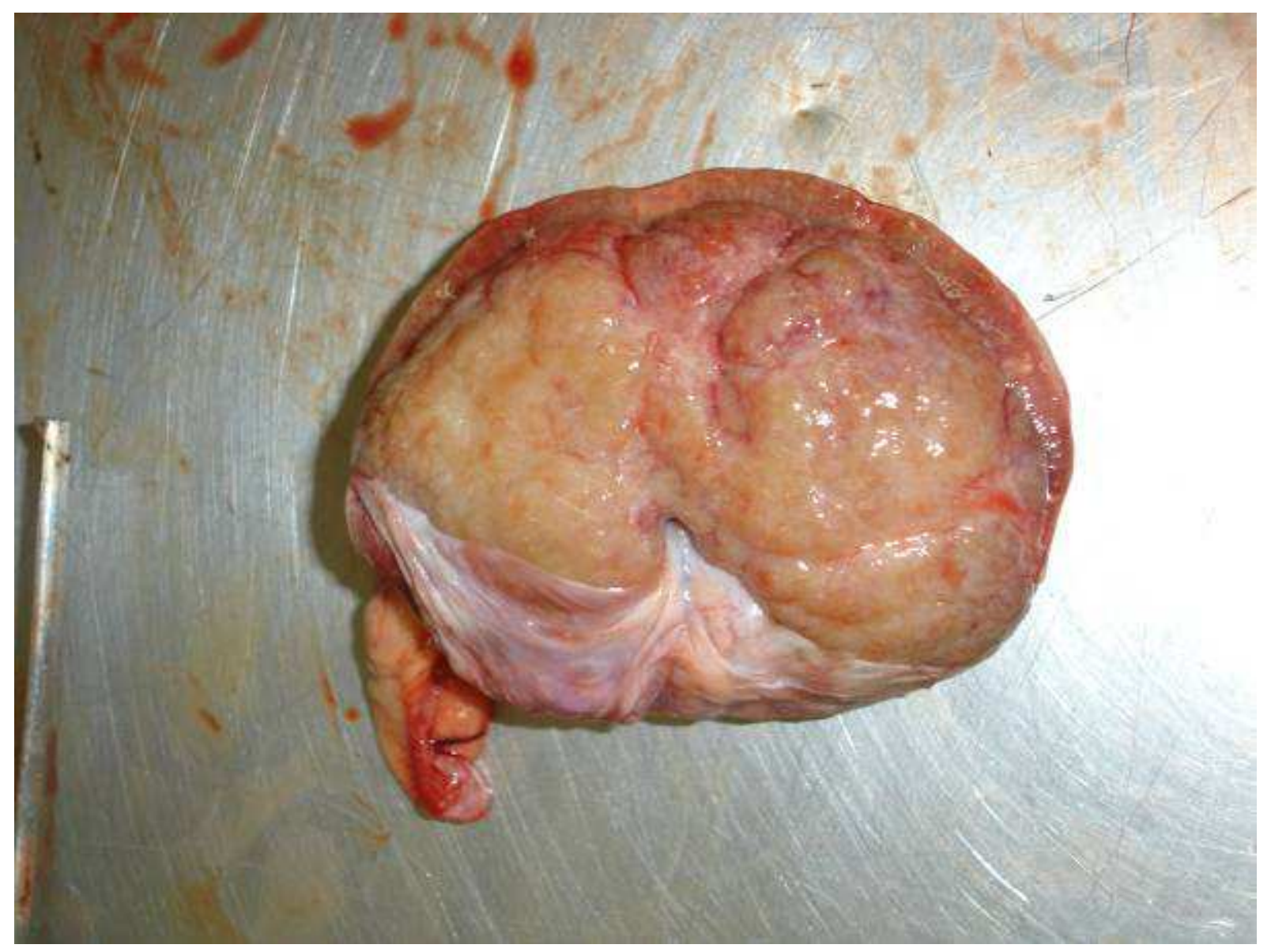

Figura 7 - Amostra renal de um cão, exemplificando rins com nefrite crônica, vista externa. Visualizar áreas com deformidade morfológica, modificando a estrutura habitual, apresentando rugosidades hiperêmicas e redução do volume da matriz renal. Fotógrafa e Proprietária da foto: Tatiane Furtado de Carvalho. 


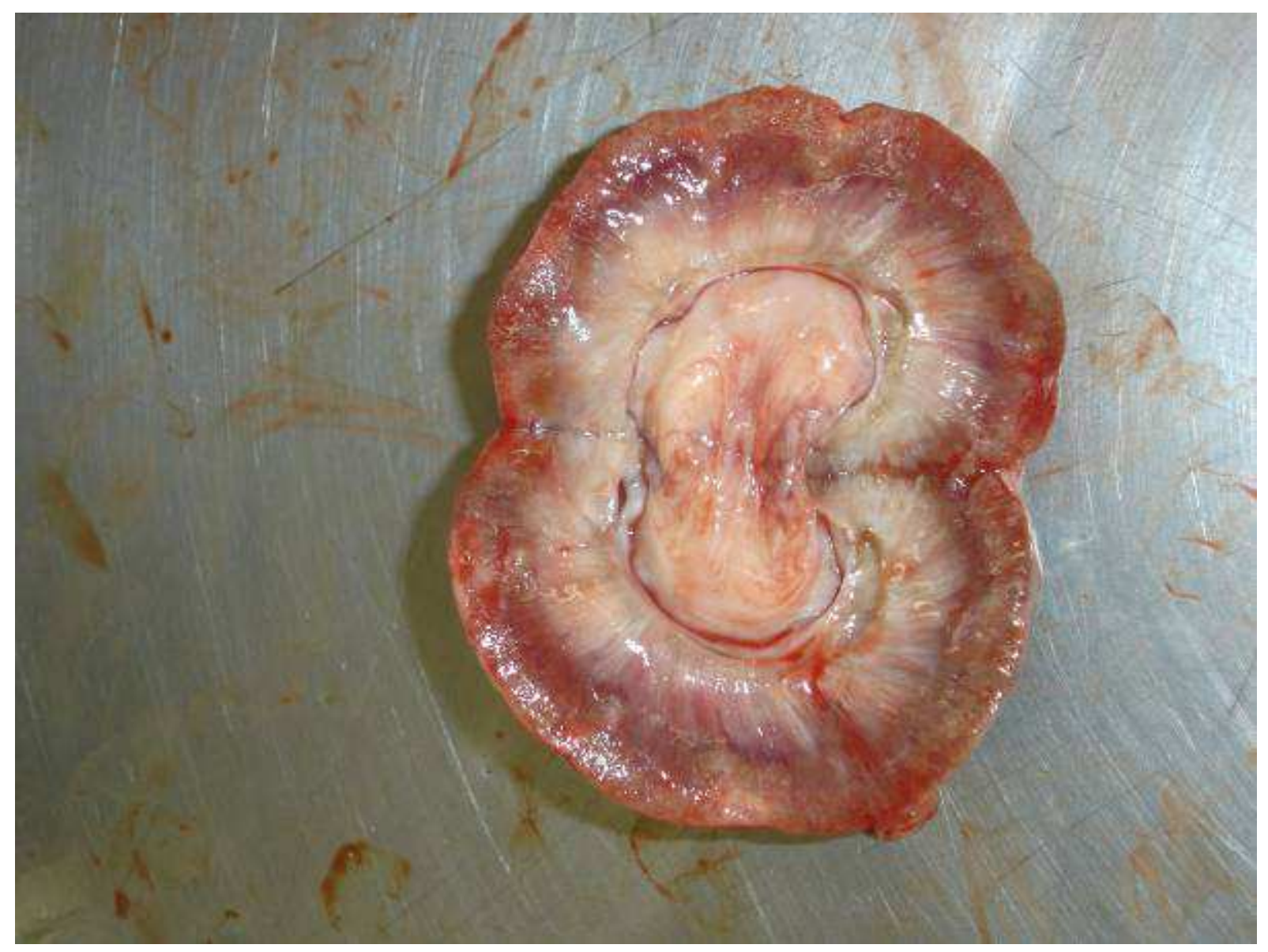

Figura 8 - Amostra renal de um cão, exemplificando rins com nefrite crônica, vista interna. Visualizar áreas com deformidade morfológica, modificando a estrutura habitual, apresentando rugosidades hiperêmicas e redução do volume da matriz renal. Áreas hiperêmicas principalmente na região cortical em transição com a região medular. Fotógrafa e Proprietária da foto: Tatiane Furtado de Carvalho.

\section{DISCUSSÃO}

Todos os animais observados, alimentados com as dietas, mista (ração e comida caseira), somente ração e somente comida caseira, apresentaram alterações renais, porém a glomerulonefrite foi de maior destaque dentre elas. Porém, mesmo com os resultados obtidos não é possível condenar a alimentação como fonte primordial das alterações renais uma vez que, em todas as dietas analisadas (mista de ração e comida caseira, somente ração e 
BARBOSA, C.H.G. et al. Alterações renais em cães alimentados com diferentes dietas. PUBVET, Londrina, V. 6, N. 34, Ed. 221, Art. 1471, 2012.

somente comida caseira) foram observadas, em sua maioria, as mesmas alterações; além disso a inespecificidade quanto aos detalhes dos alimentos que compõem a dieta fornecida pelos proprietários impede a avaliação dos teores de proteínas, compostos nitrogenados não protéicos, carboidratos, gorduras e sódio presentes nos diferentes tipos de dieta os quais seriam capazes de causar algum distúrbio renal.

As doenças renais em cães são causadas por desordens de etiologia variada que induzem alterações estruturais e funcionais dos rins, diagnosticadas por meio do quadro clínico e da histopatologia ${ }^{15}$.

A glomerulonefrite ocorre em todos os animais domésticos, observada no decurso de diferentes doenças infecciosas septicêmicas, como é o caso da erisipela e outras ${ }^{1}$. Acrescentam que o termo glomerulonefrite é tradicionalmente empregado para descrever o grupo de doenças em que a lesão primária consiste em algum tipo de anomalia estrutural do glomérulo. Apesar do sufixo "ite", a maioria dos casos não é caracterizada por alterações inflamatórias. O dano ao glomérulo pode ser grave, levando a fibrose permanente com atrofia dos túbulos associados. Alternativamente, algumas condições produzem anormalidades temporárias e, seguindo-se à resolução, há restauração da função do néfron ${ }^{16}$.

Certos pesquisadores destacam que o termo nefrite é abrangente e refere-se à inflamação do rim sem levar em consideração a localização específica da lesão ${ }^{5}$. Já a glomerulite, de acordo com outro autor, é uma inflamação dos glomérulos ou corpúsculos renais, em que microscopicamente se vê um aumento do número de células, destacando-se a presença dos mononucleares: linfócitos e plasmócitos ${ }^{6}$.

Dietas que dificultam a digestão podem interferir na metabolização e excreção de resíduos pelos rins, o que pode a médio ou longo prazo prejudicando a função renal, sobrecarregando os glomérulos. Estudiosos, viram a digestibilidade de vários suplementos protéicos vegetais e constataram que dietas contendo menores teores de oligossacarídeos, como a proteína isolada de soja e o glúten de milho, possuem maiores coeficientes de 
BARBOSA, C.H.G. et al. Alterações renais em cães alimentados com diferentes dietas. PUBVET, Londrina, V. 6, N. 34, Ed. 221, Art. 1471, 2012.

digestibilidade aparente ${ }^{17}$. Acredita-se que ao redor de $25 \%$ dos cães idosos apresentem algum comprometimento da função renal ${ }^{18,19}$, de modo que a ingestão excessiva de proteína deve ser evitada para animais nessa faixa etária. Assim, a redução da progressão da doença renal, aumento da qualidade e expectativa de vida e regularização das alterações bioquímicas relativas à insuficiência renal crônica foram conseguidas com dietas que apresentavam ao redor de $0,4 \%$ de fósforo ${ }^{20,21}$. Cães alimentados com ração revestida de polifosfatos desenvolveram $55 \%$ menos cálculo renal que animais alimentados com ração não revestida 22 .

Animais alimentados com dieta mista de ração e comida caseira, no presente estudo, foram os únicos a apresentarem retração tubular dos cilindros hialinos $(0,58 \%)$ e espessamento da capsula renal $(0,58 \%)$. Esses animais apresentaram maior índice de mineralização $(1,74 \%)$, de nefrite crônica $(1,74 \%)$ e glomerulite $(3,49 \%)$ quando comparadas com a incidência das mesmas alterações em cães alimentados com dietas diferentes.

Apenas em cães com dieta única de ração foram diagnosticados casos de degeneração turva e degeneração tubular, ambos representando $1,74 \%$ das alterações observadas. As alterações mais encontradas durante a realização desse estudo foram, respectivamente, glomerulonefrite aguda (21,51\%), nefrite intersticial $(11,05 \%)$ e degeneração hidrópica ( $8 \%)$, que segundo autor já citado, é a formação de vacúolos no citoplasma das células, especialmente dos túbulos renais, onde se acumula líquido, aspecto observado em vários processos mórbidos renais ${ }^{1}$. É explicado que nefrite intersticial é uma inflamação localizada no interstício renal, excluindo os glomérulos, podendo ser classificada em difusa ou focal ${ }^{8}$.

Foi ainda construída uma nova distribuição dos dados para fins de realização do teste de qui-quadrado $\left(\square^{\square}\right)$, na tentativa de se provar, estatisticamente, a correlação entre o tipo de dieta e as alterações renais ocorridas. As observações foram divididas em três grandes grupos, de acordo com a classificação patológica geral das alterações, hiperemia e hemorragia ficaram em grupos separados, por não se enquadrarem em nem um dos três 
BARBOSA, C.H.G. et al. Alterações renais em cães alimentados com diferentes dietas.

PUBVET, Londrina, V. 6, N. 34, Ed. 221, Art. 1471, 2012.

grupos. Os dados reagrupados ficaram divididos da seguinte maneira: 1) Alterações degenerativas: degeneração glomerular, hidrópica, turva, retração tubular e cilindros hialinos, espessamento de cápsula renal; 2) Alterações Inflamatórias: glomerulite, glomerulonefrite, nefrite aguda, nefrite crônica, nefrite intersticial, nefrite linfoplasmocitária aguda, nefrite linfoplasmocitária subaguda, pielonefrite aguda, pielonefrite crônica; 3) Alterações de Necrose: infarto renal, mineralização, necrose renal, necrose glomerular, necrose tubular, nefrose colêmica; os valores dos dados reagrupados estão descritos na Figura 9, abaixo apresentada. Entretanto a análise de $\square^{\square \square}$ não demonstrou se o tipo de dieta influenciou nas alterações renais encontradas, dando um resultado de $p>20,00$.

Figura 9 - Alterações observadas em 172 amostras renais de cães segundo sua dieta

\begin{tabular}{|c|c|c|c|c|}
\hline Alteração & & Dieta & & Total \\
\hline & Ração & $\begin{array}{l}\text { Comida } \\
\text { caseira }\end{array}$ & Mista & \\
\hline Degenerativas & 16 & 1 & 7 & 24 \\
\hline Inflamatórias & 41 & 17 & 35 & 93 \\
\hline Necrose & 19 & 2 & 9 & 30 \\
\hline Hiperemia & 7 & 3 & 3 & 13 \\
\hline Hemorragia & 7 & 2 & 3 & 12 \\
\hline Total & 90 & 25 & 57 & 172 \\
\hline
\end{tabular}

Vale ressaltar que a forma de administração da alimentação também interfere na forma como os rins vão reagir, sendo sobrecarregados ou realizando suas funções normais de filtração e excreção de metabólitos. Pesquisadores determinam que existe três métodos básicos de alimentação de cães em crescimento: ad libitum (à vontade), limitação de tempo ou limitação 
BARBOSA, C.H.G. et al. Alterações renais em cães alimentados com diferentes dietas.

PUBVET, Londrina, V. 6, N. 34, Ed. 221, Art. 1471, 2012.

da quantidade de ração ${ }^{23}$. Utilizando estas dietas que administração o animal tem um desenvolvimento sadio, com menos interferência hepática e renal.

Os animais que desenvolvem alguma alteração renal e não são diagnosticados precocemente e tratados, podem desenvolver quadros de uremia e acidose metabólica o que interfere na função dos demais órgãos. Também podem evoluir de uma insuficiência aguda para crônica, acentuando a gravidade do problema piorando o prognóstico dificultando o tratamento do enfermo. Acrescenta-se que freqüentemente, a uremia é o estado clínico em direção ao qual todas as afecções renais progressivas generalizadas convergem, sendo caracterizada por achados clínicos e laboratoriais diversos, que destacam a natureza polissistêmica da insuficiência renal crônica ${ }^{7}$. A NIC (Nefrite Intersticial Crônica) está associada à fibrose renal, que ocorre mais freqüentemente como manifestação crônica da fase de resolução de uma lesão renal preexistente e, ao lado da lesão renal crônica, é o processo patológico mais comumente reconhecido em cães, podendo, quando grave, manifestar-se clinicamente como insuficiência renal e uremia ${ }^{24}$. Complementam que muitas afecções generalizadas crônicas dos rins, que se originam em vasos, glomérulos ou túbulos estão associadas a um grau considerável de inflamação e fibrose intersticiais, e o diagnóstico morfológico de uma NIC verdadeira sugere que o distúrbio subjacente se caracteriza, predominantemente, por anormalidades morfológicas e funcionais do tecido intersticial e que, se progressivas, podem induzir a alteração nos túbulos, glomérulos, e vasos renais ${ }^{7}$.

\section{CONCLUSÃO}

Dentre os fatos apresentados, concluiu-se que o tipo de alimentação não influenciou diretamente nas alterações renais dos cães avaliados nessa pesquisa, uma vez que ambas nas três dietas a alteração mais freqüente foi a glomerulonefrite. Este fato pode ser, em parte, explicado pela inespecificidade dos valores nutricionais das diferentes dietas, a apresentação de diferentes raças, sendo que em algumas, já preexiste a facilidade para desenvolvimento 
BARBOSA, C.H.G. et al. Alterações renais em cães alimentados com diferentes dietas. PUBVET, Londrina, V. 6, N. 34, Ed. 221, Art. 1471, 2012.

de doenças no trato urogenital, o que limitou uma analise mais profunda dos dados coletados.

\section{AGRADECIMENTOS}

Agradecemos a UNIUBE, através da PROPEPE (Pro-Reitoria de Pós Graduação, Pesquisa e Extensão) e do PIBIC (Programa de Bolsas de Iniciação Científica), pela bolsa concedida e pelo apoio a pesquisa.

\section{REFERÊNCIAS}

1 - COELHO, H.E. Afecções no aparelho geniturinário. In: COELHO, H.E. Patologia

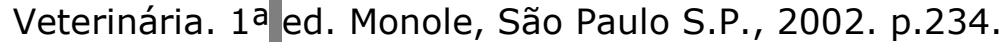

2 - ETTINGER, S.J. Moléstias renais no cão e gato. In: ETTINGER, S.J. Tratado de Medicina Veterinária. 3a ed. São Paulo, Manole editora, 1992, p. 30-51.

3 - RANDALL, D.; BURGGREN, W.; FRENCH, K. Sistema urinário. In: RANDALL, D.; BURGGREN, W.; FRENCH, K. Fisiologia animal, mecanismos e adaptações. 4.ed. São Paulo: Guanabara Koogan, 2000. p.351-372.

4 - GIOVANNI, L.H. Avaliação do cálcio sérico ionizado em gatos sadios e em gatos com insuficiência renal crônica. Dissertação (Mestrado clinica médica). FMVZ-USP São Paulo, 2003.

5 - OSBORNE, C.A.; LOW, D.G.; FINCO, D.R. Insufficient renal. In: OSBORNE, C.A.; LOW, D.G.; FINCO, D.R. Canine and Feline urology. Philadelphia, W.B. Saunders Co., 1972, pp. 4365

6 - GRAUER, G.F; LANE,I.F. Insuficiência renal aguda. In: ETTINGER, S.J.; FELDMAN, E.C.; Tratado de medicina veterinária - moléstias do cão e do gato. 4.ed. São Paulo: Manole, 1997. v.2, p.2437-2678.

7 - POLZIN, D.J.; OSBORNE, C.A.; BARTGES, J.W.; LULICH, J. P. Insuficiência renal crônica. In: ETTINGER, S.J.; FELDMAN, E.C. (Eds.) Tratado de medicina veterinária moléstias do cão e do gato. 4.ed. São Paulo: Manole, 1997. v.2, p.2394-2431.

8 - BERRNSTEIN, M. Insuficiência renal crônica em cães. Veterinária online Especialidades Médicas. Disponível em $<w w w$.veterinariaonline.com.br/especialidade.php?cdartigo $=72.2004>$ Acessado em 12 de Maio de 2009.

9 - OSBORNE, C.A., JOHNSON, K.H., PERMAN, V., SCHALL WD. Renal amyloidosis in the dog. Journal American Veterinary Medicine Association, v.153, p.669-670, 1969.

10 - SLAUSON, D.O., GRIBBLE, D.H., RUSSEL, S.W. A clinicopathological study of renal amyloidosis in dog. Journal Company Patch, v. 76, p.335-342, 1970.

11 - WATSON, A.D.J. The renal nephrotic syndrome due to renal amyloidosis in a dog. Australian Veterinary Journal, v.47, p.398-401, 1971.

12 - ClemenTS, C. A., ROGERS, K. S., GREEN, R. A., LOY JK. In: CLEMENTS, C. A., ROgeRS, K. S., GREEN, R. A., LOY JK. Splenic vein thrombosis resulting in acute anemia: an 
unusual manifestation of nephrotic syndrome in a chinese Shar-Pei with reactive amyloidosis. Journal American Animal Hospital Association, v.31, p.411-415, 1995.

13 - PRIOR, J. Situação atual e perspectivas do mercado nacional de alimentos pet. In: simpósio sobre nutrição de animais de estimação, no 3. 2003, Campinas. Anais. Campinas: Colégio Brasileiro de Nutrição Animal, 2003. p.1-4.

14 - SCOTT, D.W.; MILLER, W.H.; GRIFFIN, C.G. Doenças cutâneas nutricionais. In: MULLER \& KIRK, Dermatologia de Pequenos Animais, $5^{\circ}$ ed. Rio de Janeiro: Interlivros, 1996. p.832-842.

15 - SPARgOS, B.H.; HAAS, M. The kidney. In: RUBIN, S.I.; FABER, J.L. Pathology. 2.ed. Philadelphia: J.B. Lippincott, 1994. p.804-865.

16 - STEVENS, A.; LOWE, J. Doenças do sistema urinário. In: . Patologia. 2.ed. São Paulo: Manole, 1998. p.317-349.

17 - YANKA, R.M.; JAMIKORN, U.; TRUE, A.D.; HARMON D.L. Evaluation of soybean meal as a protein source in canine foods. Animal Feed Science and Thecnology, v.109, p.121$132,2003$.

18 - CROWELL, W.A.; FINCO, D.R. Frequency of pyelitis, pyelonophritis, renal perivasculitis and renal infarction in dogs. American Journal of Veterinary Research, v.36, p.111-114, 1975.

19 - DEBRAEKEEKER, J.; GROSS, K.L.; ZICKER, S.C. Feeding older dogs. Geriatrics and renal diseases: nutrition management of older pets. Kansas: Hills Pet Nutrition, 1999, p.21-32.

20 - KRONFELD, D.S. Dietary management of renal senescence and failure in dogs. Australian Veterinary Journal, v.71, p.328- 331, 1994.

21 - FINCO, D.R.; BROWN, S.A.; CROWELL, W.; DUNCAN R.J.; BARSANTI J.A.; BENNETT S.E. $A$. Effects of dietary phosphorus and protein in dogs with chronic renal failure. American Journal Veterinary Research., v.53, p.2264-2271, 1992.

22 - COX, E.R.; LEPINE, A.J.; CAREY, D.P. Influencias nutricionales en la salud dental del perro. Revista Medica Veterinaria Buenos Aires, v.83, p.265- 272, 2003.

23 - RICHARDSON, D.C.; TOLL, P.W. Relationship of nutrition to developmental skeletal disease in young dogs. Veterinary Clinical Nutrition, v.4, p.6-13, 1997.

24 - CONFER, A.W.; PANCIERA, R.J. Sistema urinário. In: CARLTON, W.W.; McGAVIN, M.D. (Ed.). Patologia veterinária especial de Thomson. 2.ed. São Paulo: Artmed, 1998. p.228- 265. 